\title{
A ÉTICA DA PÓLIS: REFLEXÕES SOBRE A IGUALDADE COMO PRINCÍPIO DE JUSTIÇA
}

\section{THE ETHICS OF POLIS: REFLECTIONS ON EQUALITY AS A JUSTICE PRINCIPLE}

\author{
${ }^{1}$ Lívia Teixeira Moura Lobo \\ ${ }^{2}$ Paulo Sergio Weyl Albuquerque Costa
}

\section{RESUMO}

O artigo objetiva refletir sobre a Igualdade, como princípio ético a ser observado na comunidade política, nas teorias de igualdade liberal desenvolvidas pela filosofia política de John Rawls, Ronald Dworkin e Amartya Sen, respectivamente autores de "Uma Teoria da Justiça", "A Virtude Soberana" e "Desigualdade Reexaminada". As obras são analisadas sob o prisma do que as une, isto é, a igualdade como elemento imprescindível para alcançar a justiça, sendo o mote do estudo refletir a ética da inserção deste ideal em concepções políticas liberais. Ousa-se, ainda, a realização de considerações acerca da importância do tema para a filosofia do direito.

Palavras-chave: Igualdade, Justiça, Política, Ética, Igualdade liberal

\section{ABSTRACT}

This article reflects on the Equality, as ethical principle to be observed in the political community, in the liberal equality theories developed by the political philosophy of John Rawls, Ronald Dworkin and Amartya Sen, authors of "A Theory of Justice", "The Sovereign Virtue" and "Inequality Re-examined". The works are analyzed through the prism of what unites them, which is the equality as essential element for achieving justice, being our goal to reflect the ethics of this ideal in liberal political views. In this study there is also a consideration about the importance of the topic for the philosophy of law.

Keywords: Equality, Justice, Politics, Ethics, Liberal equality

\footnotetext{
${ }^{1}$ Doutorado em Direito pela Universidade Federal do Pará, Pará (Brasil) E-mail : livia.tmoura@ yahoo.com.br

${ }^{2}$. Doutor em Direito pela Pontifícia Universidade Católica do Rio de Janeiro, Rio de Janeiro (Brasil). Professor Associado da Universidade Federal do Pará, Pará (Brasil) E-mail: psweyl@ hotmail.com
} 


\section{1 - INTRODUÇÃO}

A desigualdade é a realidade. O mundo é desigual. Não haveria nenhum problema nas afirmações realizadas, a não ser que estas fossem sinônimo de injustiça social. É exatamente este o mote do trabalho: evidenciar a igualdade, não a homogeneidade, nas teorias liberais de John Rawls, Ronald Dworkin e Amartya Sen como um ideal ético da comunidade política justa.

Diante da notícia, de janeiro de 2014, sobre a reunião do Fórum Econômico Mundial e a conclusão chegada a partir dos debates, de que "Uma crônica disparidade entre ricos e pobres está se ampliando" (Hirscheler, Agência Reuteurs, Estadão), percebe-se que na meditação acerca da realidade "a reflexão moral aflora naturalmente quando nos vemos diante de uma difícil questão de natureza moral” (SANDEL, 2013, p. 36).

Desta forma, em concebendo, como exemplo, a pobreza de alguém em contraponto com a riqueza de outrem, de modo que um viva em situação de miséria e outro em condições de opulento luxo, é de se questionar se esta contradição é algo certo e bom e, à opinião ou convicção sobre o que é certo fazer, tal como ensina Sandel (2013, p. 37-38), deve ser adicionado o questionamento acerca da razão da determinada opinião ou convicção, como em um diálogo moral que remonta à Sócrates e à filosofia moral de Aristóteles.

O exercício dialético apontado por Sandel (2013, p. 38) é também por ele desafiado, quando indaga se tal ponderação pode levar à justiça ou verdade moral e se o alinhamento de todas as intuições morais dos indivíduos com os princípios que fundamentam sua conduta levaria à confiança de que o resultado "seria algo mais do que um amontoado de preconceitos com coerência interna.", ao que responde "a reflexão moral não é uma busca individual, e sim coletiva.”, acrescentando (2013, p. 39): “Quando a reflexão moral se torna política, quando pergunta que leis devem governar nossa vida coletiva, precisa ter alguma ligação com o tumulto da cidade, com as questões e os incidentes que perturbam a mente pública.”.

Ora, uma notícia veiculada por uma agência internacional - Reuteurs - sobre um fórum constituído por líderes da economia mundial, parece apontar para um sucesso que perturba a "mente pública" e, embora, as teorias a serem abordadas neste artigo não se refiram aos sistemas políticos do mundo, relacionando-se ao liberalismo político, refletem sobre um problema de relevância mundial. Logo, abordar a igualdade como ideal ético é também relevante, além de atual e concernente à vida prática. 
Para Robinet (2004, p. 134), as questões morais são, tal como já salientara Sandel, as mais comuns, configurando-se a moral em um fato social, ou o fato de as pessoas viverem em uma comunidade determinada por costumes, tradição e mentalidade: "O indivíduo vive primeiramente sem distância, sem recuo na moral concreta, naquilo que Hegel chama "substância ética."”,

Segundo Abbagnano (2007, p. 380), em geral, “ética" é a ciência da conduta, podendo esta concepção ser aprofundada como a ciência do fim para o qual a conduta humana deve se dirigir e dos meios que levam até este fim, entendendo-se fins e meios como natureza do homem. A noção de "bem" imbricada na percepção adotada é a de bem como o que é, pelo fato de que é, deduzindo-se daí a ideia aristotélica de "felicidade como o fim da conduta humana, dedutível da natureza racional do homem."

A compreensão aristotélica de política também é explicitada por Abbagnano (2007, p. 773) como uma investigação ética sobre o que deve ser o bem e o bem supremo, que determinará quais as ciências necessárias para as cidades e quais devem ser aprendidas por cada cidadão.

Norberto Bobbio (1998, p. 954) informa ser o termo "Política" derivado do termo pólis - "cidade autônoma e soberana, cujo quadro institucional é caracterizado por uma ou várias magistraturas, por um conselho e por uma assembleia de cidadãos" (conceito também elucidado por Bobbio na página 949) - e, como se faz claro, refere-se à cidade.

Então, quando se investiga a ética - como substância do que "subsiste ao tempo, do fundamento e o ponto de partida, aquilo de que o indivíduo tira o necessário para ser (...)" (ROBINET, 2004, p. 134) - que constitui a pólis, isto é, as instituições que disciplinam e organizam a vida em sociedade, está-se diante daquilo que o título do artigo comunica: “A ética da pólis" ou da política.

A segunda parte do título, "Reflexões sobre a igualdade como princípio da justiça", guarda em si indagações sobre como as teoria de igualdade liberal, já mencionadas, situam a igualdade na política: Por que a igualdade importa para a ética da comunidade política?

As respostas a estes questionamentos far-se-ão a partir da apresentação, em linhas gerais, das ideias de Rawls, Dworkin e Sen sobre igualdade; da elucidação acerca das leis éticas e do raciocínio ético como fundamento das ações que levam ao bem supremo, em Kant e Aristóteles; e do diálogo das teorias de igualdade liberal com as concepções éticas abordadas. Será apresentado, ainda, breve comentário acerca do direito relacionado ao tema e, por fim, as conclusões. 


\section{2 - AS TEORIAS DE IGUALDADE LIBERAL: RAWLS, DWORKIN E SEN}

A fim de elucidar como as teorias de igualdade liberal, por este trabalho abordadas, refletem sobre a igualdade, como princípio da justiça, breves explanações serão desenvolvidas sobre a temática. Quando diz-se breve não se quer dizer em pouquíssimas linhas, dada a complexidade na tratativa do assunto, sempre conduzido com o encadeamento cuidadoso e lógico do texto e com alinhamento das ideias, no decorrer dos capítulos, que confirmam a igualdade como um princípio inerente à justiça. Além disso, há a utilização de terminologias próprias a cada obra, sendo, talvez, as mais complexas aquelas empregadas por Sen, ao passo que Rawls e Dworkin, demandam mais cuidado na leitura porque usam de situações artificiais para introduzir e fazer entender seus pensamentos.

É de se frisar, ainda, que este trabalho não enseja um cotejo para declarar a superioridade de ideias, como é possível observar na introdução; o almejado, em verdade, é extrair o ideal ético das teorias para o qual se volta igualdade, aventando-se, desde já, a hipótese de que seja o mesmo para todas as concepções, isto é, o bem supremo, a felicidade cujo alcance se dá por meio da justiça.

\section{1 - “UMA TEORIA DA JUSTIÇA” DE JOHN RAWLS}

A primeira sessão da obra de Rawls já coloca muito claramente uma ideia que o autor melhor explicará no decorrer dos capítulos e que, como não poderia deixar de ser, funda a sua teoria: a de que a justiça é a virtude primeira das instituições sociais, impedindo a vulnerabilização de pessoas em nome do bem estar do resto da sociedade. É sob essa base que Rawls (2008, p.4), como filósofo que é, faz suas indagações, a começar pelo papel dos princípios da justiça, logo acrescentando que estes devem definir direitos e deveres nas instituições básicas da sociedade, definindo também, apropriadamente, sobre as parcelas distributivas e, desse modo, estabelecendo uma perspectiva comum sobre quais reivindicações distintas serão julgadas.

Esta estrutura básica da sociedade, dentro da teoria, estaria isolada de qualquer outra e seria bem-ordenada, isto é, todos agiriam de maneira justa, fazendo sua parte para que as instituições também permaneçam justas, como em uma teoria da obediência estrita ideal que permitisse a avaliação dos aspectos distributivos da sociedade. (RAWLS, 2008, p.9)

É bastante evidente que na doutrina rawlsiana (2008, p. 15) a grande tarefa é a escolha dos princípios na posição original hipotética, em que as pessoas ainda não conhecem 
seu lugar na estrutura básica da sociedade, impendendo relevar serem os indivíduos, na dada posição, mutuamente desinteressados, não preocupados com os interesses alheios, mas com os seus, além de serem racionais.

A concepção de mútuo desinteresse leva o autor (2008, p. 25-33) a duvidar sobre a possiblidade de escolha do princípio da utilidade pelas partes interessadas em si mesmas, afinal a máxima de tal princípio é parte da teoria Utilitarista e prega a elevação social do prazer em detrimento da dor, ainda que uma parcela da comunidade precisasse ser sacrificada em seu próprio prazer para beneficiar a maioria. O raciocínio para a denegação da utilitarismo é o de que a situação de igualdade em que se encontravam as partes na posição original permitiria a estas fazer exigências recíprocas, portanto não caberia a opção por um princípio em que uns teriam perspectivas inferiores de vida para que a maior soma de vantagens pudesse ser usufruída por outrem, afinal qualquer dos indivíduos poderia ser a parte sacrificada descrita pela razão utilitária, conforme fosse sorteada para tal na loteria natural da vida.

As diferenças entre os sujeitos são preocupações tão valorosa à Teoria da Justiça que o seu contratualismo - o acordo social a ser feito na posição original - gira neste eixo, ou seja, para destacar a pluralidade tão comum à humanidade, de maneira que, definidos os princípios da justiça, estes considerem esta diversidade. Ademais, enquanto o auto-respeito é um bem de disputa utilitária, ou seja, quanto mais se alcança a satisfação dos desejos é maior a possibilidade de sujeitar e discriminar alguém, diminuindo-lhe o auto-respeito, na justiça como equidade a satisfação de ver o outro em situação pior, simplesmente, não atende aos princípios da justiça, o bem não precede o justo, mas o contrário, tal como numa proposição deontológica. (RAWLS, 208, p. 33-36)

Os princípios da justiça são peças chaves para realização da justiça substantiva ou material, senão vejamos. As instituições da estrutura básica da sociedade podem, apoiando-se em qualquer princípio, aplicar de maneira imparcial e coerente as leis, em uma justiça formal que se dirige de igual maneira a todas as pessoas. A adoção dos princípios da justiça como equidade, todavia, não se orienta para a simples solução de casos semelhantes de forma semelhante, mas conduz a sociedade à justiça substantiva. Para fins de maior elucidação, parte-se à conceituação dos princípios tal como Rawls os define inicialmente:

Primeiro: cada pessoa deve ter um direito igual ao sistema mais extenso de iguais liberdades fundamentais que seja compatível com um sistema similar de liberdades para as outras pessoas. 
Segundo: as desigualdades sociais e econômicas devem estar dispostas de tal modo que tanto (a) se possa razoavelmente esperar que se estabeleçam em benefício de todos como (b) estejam vinculadas a cargos e posições acessíveis a todos. (2008, p. 73).

Como é possível observar, o primeiro princípio estabelece que as liberdades fundamentais (liberdade política, liberdade de expressão e reunião, liberdade de consciência e de pensamento, liberdade individual, direito de propriedade, proteção contra prisão arbitrária.) devem ser iguais entre as pessoas, enquanto o segundo princípio se ocupa com a distribuição de renda e riqueza de modo que seja vantajosa para todos, ao mesmo tempo em que os cargos de autoridade e funções de responsabilidade sejam acessíveis a todos.

Vale salientar que os princípios se dispõem em ordem serial, como justifica o autor em questão (2008, p. 49), havendo prioridade do primeiro sobre o segundo, porque não é admissível violar as liberdades fundamentais ao argumento de que haverá obtenção de maiores vantagens sociais e econômicas. O que não quer dizer, por conseguinte, que tais liberdades são absolutas, pois o choque entre elas, e somente neste caso, poderia conduzir a uma limitação ou comprometimento.

Ao empreender interpretações sobre o segundo princípio, Rawls (2008, p. 91-101) adota a interpretação da igualdade democrática, combinando a igualdade equitativa de oportunidades com o princípio da diferença, resultando na concepção de que "as expectativas mais elevadas dos que estão em melhor situação serão justas se, e somente se, fizeram parte do esquema que eleve as expectativas dos membros mais desfavorecidos da sociedade." (2008, p. 91).

Tal como exposta, a interpretação da igualdade democrática aplaca a influência das contingências naturais, caracterizando-se como fortemente igualitária, pois, em havendo uma distribuição, a situação de todos, dentro do esquema dos contemplados na estrutura básica da sociedade, deve melhorar, porque não há ganho sem que isso ocorra. Além disso, Rawls, em seu propósito de tornar sua teoria realmente aplicável no espaço e no tempo, propõe a justiça entre gerações, alvitrando sobre quanto deve ser poupado de uma geração para outra, considerando o direito das gerações imediatamente subsequentes de reivindicar aos seus antepassados uma poupança justa. Assim, o princípio da diferença passa a se configurar da seguinte forma:

\footnotetext{
As desigualdades sociais e econômicas devem estar dispostas de tal modo que tanto (a) se estabeleçam para o máximo benefício possível dos menos favorecidos que seja compatível com as restrições do princípio da poupança justa, como (b) estejam vinculadas a cargos e posições abertos a todos em condições de igualdade equitativa de oportunidade. (2008, p. 376).
} 
A igualdade equitativa é, então, um meio para que o sistema de cooperação social seja uma forma de justiça procedimental pura, pois é uma forma de assegurar que o produto da distribuição sempre será positivo ao se atender à apropriada aplicação do procedimento. (RAWLS, 2008, p. 101)

As expectativas, sobre as quais o autor (2008, p. 108) se refere, e cuja satisfação por parte dos mais favorecidos deve refletir positivamente para os menos favorecidos, tem por base a auferição de bens primários, isto é direitos, liberdades, oportunidades, renda e riqueza. Tais bens são racionalmente e prioritariamente desejáveis, ajudando na promoção dos objetivos dos indivíduos.

Mas em quais posições, dentro da estrutura básica da sociedade, os indivíduos deveriam estar/alcançar para que os princípios da justiça sejam concretizados? Nas posições sociais relevantes que, dentre uma multiplicidade de posições sociais são as principais para a coerência da teoria e para a análise correta das plúrimas reinvindicações. (RAWLS, 2008, p.

No que se refere ao primeiro princípio, a liberdade, Rawls (2008, p.115) afirma ser a cidadania igual a posição social relevante, pois é definida pelos direitos e liberdades e, quando cumpridos os dois princípios todos os cidadãos são iguais e, portanto, todos estão na mesma posição social relevante, de onde se pode ter um ponto de vista geral.

Mas as vezes a justiça como equidade pode precisar dispor de outras posições sociais, como em casos em que as consequências distributivas são irrelevantes. Nestes casos utiliza-se o princípio do interesse comum que classifica as instituições levando em conta sua efetividade em garantir condições para que os indivíduos promovam seus objetivos e tal promoção gere benefícios semelhantes para o corpo social, mas neste caso os indivíduos com maiores expectativas serão os menos atendidos. (RAWLS, 2008, P. 115).

\section{2 - “A VIRTUDE SOBERANA” DE RONALD DWORKIN}

A obra "A Virtude Soberana" de Dworkin trata sobre a teoria e a prática da igualdade, conforme subtítulo do livro em sua tradução para o português. Para o autor (2011, p. 3-4), a igualdade é um ideal político que causa mistério, sendo mote de sua teoria declarar que forma de desigualdade é decisivamente importante, como resolução de um problema de igualdade distributiva, supondo-se que uma comunidade escolherá entre esquemas de distribuição de dinheiro ou recursos para os indivíduos, de maneira que tal esquema trate a todos com igualdade. 
Esta tratativa sobre igualdade distributiva defendida por Dworkin $(2011$, p. 4) pautase na igualdade de recursos, na qual as pessoas são iguais quando há a distribuição ou transferência de recursos, tal que nenhuma transferência adicional seja capaz de permitir maior igualdade de suas parcelas do total de recursos. Tal concepção se opõe à igualdade de bem-estar, em que o esquema distributivo concebe as pessoas como iguais quando distribui ou transfere recursos até que nenhuma transferência adicional possa deixá-las mais iguais em bem-estar.

A primazia dada à igualdade de recursos, considerando os recursos privados dos indivíduos, torna o mercado econômico uma ferramenta analítica que atribui preço a uma grande variedade de bens e serviços e que, portanto, deve figurar no núcleo de qualquer elaboração teórica atraente da igualdade de recursos, como uma condição necessária da liberdade individual. (DWORKIN, P. 81-82).

Para elucidar sua "igualdade de recursos" o autor constrói um experimento artificial para abstrair da teoria contingências concernentes ao mercado e à política a serem enfrentados posteriormente. Supondo um grupo de náufragos em uma ilha desabitada com recursos em abundância, Dworkin (2011, p. 81) impõe que ninguém possui direito prévio a tais recursos e que, portanto, estes devem ser divididos igualmente para passarem no teste da cobiça, no qual "Nenhuma divisão de recursos será uma divisão igualitária se, depois de feita a divisão, qualquer imigrante preferir o quinhão de outem a seu próprio quinhão.”.

O teste da cobiça, alerta Dworkin (2011, p. 83-84), não se satisfaz com a simples divisão mecânica de recursos, então o autor entende pela necessidade de algum tipo de leilão ou outro método de mercado para resolver a questão. Adotando o leilão hipotético, parte-se à ideia de que cada imigrante receberá um número igual de conchas, cujo propósito é servirem de fichas para a compra de qualquer coisa na ilha, exceto as próprias pessoas. Somente desta maneira a distribuição passará pelo teste de cobiça, pois "ninguém cobiçará as compras de ninguém, porque, hipoteticamente, poderia ter comprado tal porção com suas conchas, em vez da porção que comprou."

Algo muito relevante para entender a igualdade na teoria dworkiniana (2011, p. 85) é observar as pontuações do autor, caso os migrantes houvessem optado por estabelecer um regime de igualdade de bem-estar, neste caso, o leilão não seria como o descrito supra, seria um mecanismo para eliminar as diferenças, dando-se atenção ao bem-estar das pessoas como um todo e não ao bem-estar oriundo ou perdido de uma determinada fonte, consecutando na 
possibilidade de duas pessoas deterem o mesmo bem-estar, embora seu bem estar-social não fosse o mesmo (2011, p. 9/10).

Diante da opção pelo leilão para a igualdade de recursos, está-se em frente à igualdade distributiva que não oferece homogeneização das preferências de cada pessoa, mas as mune de informações quanto ao custo que suas escolhas imporão às outras pessoas e ao estoque total de recursos por elas utilizados equitativamente, não servindo como fundamento para refutar a distribuição dizê-la desigual quanto às contingências de matéria prima ou gostos, pois a métrica da distribuição igual é indagar sobre a real importância dos recursos para os outros, deduzindo-se daí que cada indivíduo possui seu justo quinhão de recursos, podendo levar a vida desejada, contanto que esteja de acordo com o comando da justiça. (2011, p. 86).

O leilão fomentará, assim, uma igualdade de recursos inicial, não resistindo o teste da cobiça quando os planos de vida e a sorte das pessoas impactarem nos recursos escolhidos. Para isso, Dworkin (2011 p. 90-101) estabelece os seguros compulsórios como meios de compensação da sorte bruta, isto é, aquela relacionada a resultado de riscos de apostas não deliberadas, tal como a má sorte de nascer com uma doença grave, por exemplo.

A compensação, elucidada supra, busca remediar um aspecto injusto que nada tem a ver com as apostas pessoais em riscos calculados, tal como o dispêndio de valores em razão de determinados gostos individuais, afinal, as pessoas com tais gostos não possuem menos recursos à disposição, mas os indivíduos privados de determinadas faculdades físicas e mentais, que poderiam ser utilizadas junto às faculdades materiais para a realização de seu plano de vida, padecem da restrição dos recursos que são essas faculdades físicas e mentais. (2011, p. 100-101)

Outra forma de correção das distribuição inicial do leilão, voltada para que cada indivíduo possua o mínimo de recursos para viver mesmo com as perturbações da produção e do comércio, seria a "redistribuição periódica dos recursos por meio de algum imposto de renda."(2011, p. 115), sempre considerando que as diferenças de aspirações de cada pessoa, como relevantes para o leilão, não podem ser superadas por essa redistribuição periódica, isto é, “Convém elaborar um esquema de redistribuição, na medida do possível, que neutralize os efeitos dos talentos diferentes, mas preserve as consequências da escolha de ocupação segundo a noção que a pessoa tem do que deseja fazer da vida." (2011, p. 115).

Note-se que toda a teoria da igualdade de recursos visa manter as diferenças entre os indivíduos, isto é, a igualdade distributiva não almeja uma homogeneização do bem-estar, as 
pessoas promovem a distribuição dos recursos no leilão para executar os planos de vida que bem lhes aprouver, não para terem um saldo de recursos igual, independentemente de suas aspirações. Isso é preponderante, pois a igualdade, como virtude soberana, não se alija da tradição liberal em que é ético que cada um tenha a responsabilidade de conduzir sua vida.

Assim, a liberdade para Dworkin (2011, p. 158-159) não conflita com a igualdade, mas é um aspecto da igualdade distributiva, sendo valiosa pelas consequências que acarreta na vida das pessoas e não por si só, tal como uma obra de arte. A liberdade importa na medida em que permite ao processo de distribuição igualitária não depender unicamente dos resultados passíveis de serem avaliados conforme a preferência ou satisfação, mas também em acordo com a responsabilidade assumida pelas próprias aspirações e projetos diante de uma comunidade de igual consideração, onde o preço dos planos de um reverbera nos planos de outras pessoas.

O entendimento quanto ao pertencimento a uma comunidade de igual consideração impediria que, em um conflito entre liberdade e igualdade, a liberdade tivesse prevalência, pois isso acarretaria em agir de modo a não demonstrar igual consideração por todos os cidadãos, negando-se, por conseguinte, o princípio igualitário abstrato, isto é, "o governo deve agir para tornar melhor a vida daqueles a quem governa, e deve demonstrar igual consideração pela vida de todos.” (2011, p. 169). Dessa forma, a liberdade teria valor porque a vida vivida em liberdade possui mais valor, nesta senda o princípio igualitário abstrato requer que o governo cuide da liberdade para que tenha consideração pela vida daqueles que governa (2011, p. 171).

\section{3 - "DESIGUALDADE REEXAMINADA" DE AMARTYA SEN}

Amartya Sen (2008, p. 43) inicia seu livro colocando a igualdade como um problema ético ao pontuar as questões "Por que igualdade?" e "Igualdade de quê?" como indagações éticas, acrescentando que em toda teoria normativa do ordenamento social, a qual resista ao tempo, aparece a exigência acerca da igualdade de algo.

A partir do elenco de várias teorias éticas de justiça, Sen (p. 45) conclui que ser igualitário, em um espaço ao qual se conceda grande importância, não é uma característica unificadora, ao contrário:

Querer igualdade de alguma coisa - algo visto como muito importante - é sem dúvida uma semelhança de algum tipo, mas esta semelhança não coloca os grupos combatentes do mesmo lado. Só mostra que a batalha não é, num sentido importante sobre "por que igualdade?", mas sobre "igualdade de que?”. (SEN, 2008, p. 47) 
Os seres humanos são distintos tanto em características relativas ao ambiente natural, quanto social, além das diferenças de características pessoais como sexo, idade, aptidões físicas e mentais, sendo uma das consequências das diferenças entre as pessoas, a igualdade de um fato estar aliada à desigualdade em outro (2008, p. 51). A partir do entendimento da necessidade de uma igualdade de base, o autor em questão (2008, p. 52) entende que a pergunta “igualdade de que?" não difere da questão "qual é o espaço correto para a igualdade basal?", pois a resposta terá consequências de longo alcance sobre os padrões distributivos nos outros espaços, inclusive no que se refere às necessárias desigualdades.

Sen (2008, p. 54), tal como Dworkin, não vê conflito entre liberdade e igualdade, não as entendendo como categorias alternativas, pois "a liberdade está entre os possíveis campos de aplicação da igualdade, e a igualdade está entre os possíveis padrões de distribuição da liberdade.".

Comentando sobre liberdade e escolha, o autor (2008, p. 69) percebe que uma realização de fato conseguida se liga ao que se faz ou se alcança, para tal, é necessário avaliar a oportunidade real existente de obter aquilo valorizado por cada um, isto é, a liberdade para realizar, podendo ser a desigualdade patente tanto no que se relaciona às realizações, quanto na liberdade.

Ao considerar que igualar a parcela de recursos ou a parcela de bens primários não, necessariamente, iguala as liberdades substantivas a serem usufruídas por pessoas diferentes, considera, também, a possibilidade de haver variações significativas na conversão de recursos e bens primários em liberdades e a impossibilidade de se ter oportunidade real para se alcançar o que se valoriza (2008, p.72-73). Nesta senda, Sen (2008, p. 74) considera recursos e bens primários meios para a liberdade e as diferenças interpessoais e sociais como elementos capazes de tornar variável a conversão de recursos e bens primários em liberdade para realizar.

Para elucidar com mais profundidade a liberdade para realizar e as realizações, Sen (2008, p. 79) começa explicando o bem-estar como a qualidade do "estado" de uma pessoa. Nesta percepção, viver seria um conjunto de "funcionamentos" inter-relacionados, entendendo-se por funcionamentos desde a boa saúde até ser feliz. A realização de uma pessoa, por conseguinte, seria o vetor de seus funcionamentos. Logo estes constituiriam o estado de uma pessoa e a partir de sua apreciação/avaliação poder-se-ia configurar o bemestar. 
Atrelada à noção de funcionamentos está a capacidade para realizar tais funcionamentos, representando suas várias combinações ou um conjunto de vetores de funcionamento que refletem a liberdade da pessoa para levar determinado tipo de vida. " $\mathrm{O}$ "conjunto capacitário" reflete, no espaço de funcionamentos, a liberdade da pessoa para escolher dentre vidas possíveis.”(2008, p.80). Assim, se os funcionamentos realizados se configuram no bem-estar de alguém, então a capacidade para realizar os funcionamentos é a liberdade da pessoa (ou oportunidades reais) para ter bem-estar.

Assim, esta ligação entre capacidade e bem-estar consiste no fato de que fazer o próprio bem-estar realizado depende da capacidade de realizar funcionamentos, logo, a realização de bem-estar é dependente do processo através do qual se realizam os vários funcionamentos e das decisões de cada um para essas escolhas, o que remete à possibilidade de escolher como uma parte valiosa de viver; poder ter escolhas genuínas representaria ter uma vida mais valiosa, rica. (SEN, 2008, p. 81)

A realização de objetivos e valores que a pessoa tem razão para buscar relaciona-se à condição de agente de alguém, podendo tais objetivos e valores necessários estar ligados ou não ao bem-estar desta pessoa. (SEN, 2008, p. 103).

Sen (2008, p. 111-112) passa, então, a questionar se o aumento nas escolhas que se pode ou se deve fazer precisa ser visto como aumento de liberdade, o que se reveste em um ponto central para a avaliação das estruturas sociais e políticas públicas relacionadas com o ganho de liberdade. Deparar-se com mais alternativas, assim, não significa sempre uma expansão da liberdade para se fazer o que se valoriza, a expansão das escolhas pode ser tanto uma oportunidade, quando as escolhas podem ser feitas pelas pessoas, como um ônus, quando as escolhas devem ser feitas pelo indivíduo. Há, então diferentes tipos de liberdade e uma exigência impassível de escape de valoração na avaliação da liberdade.

A complexidade social dificilmente permite que cada pessoa tenha todos os instrumentos de controle (os controles são exercidos segundo o que valorizamos e queremos, seguindo decisões contrafactuais, dando à pessoa maior liberdade para levar a vida que escolheu) de sua vida, então, afirma Sen (p.114), "Se não temos controle sobre o processo de eliminação de epidemias, no que diz respeito à nossa 'liberdade como controle', não há nada mais a ser dito neste campo. Porém, num sentido mais abrangente, o problema da liberdade ainda está aí.".

O autor (2008, p. 115) percebe, pois, que a avaliação das liberdades desfrutadas mostra o quanto os indivíduos são desiguais e que a base informacional da avaliação deve 
considerar as escolhas contrafactuais e a sua relação com o que se faz acontecer, havendo, pois, uma exigência pesada quanto às informações para analisar as liberdades. Acentua Sen (2008, p. 118) que quando se avaliam as desigualdades na capacidade de escapar de doenças que não são inevitáveis ou da fome que pode ser evitada, não se está avaliando somente diferenças de bem-estar, mas as liberdades básicas valorizadas e apreciadas.

Comentando que a base informacional de um juízo informa os dados dos quais o juízo é completamente dependente, Sen (p. 127) destaca como base informacional do juízo de justiça os conteúdos substantivos de teorias da justiça, apontando cada teoria como inclusiva da escolha de uma exigência particular de "igualdade basal" que, por conseguinte, influenciará na escolha da variável focal para evitar a desigualdade, então, as concepções de justiça possuem profunda conexão com concepções de igualdade.

Na compreensão de justiça de "Desigualdade reexaminada" (2008, p.136-138), as pretensões individuais devem ser avaliadas em termos de capacidades, pois a liberdade real seria representada pela capacidade "real de uma pessoa para realizar várias combinações alternativas de funcionamento. A capacidade reflete a liberdade de uma pessoa para escolher entre combinações de funcionamentos ou vidas alternativas e a valoração não precisa pressupor um conjunto específico de valores.

A avaliação das desigualdades deve considerar, pois, a pluralidade de espaços nos quais a desigualdade pode ser apreciada, tal como a diversidade de indivíduos, ou seja, as vantagens e desvantagens que as pessoas tem, em uma comparação, podem ser vistas sob diferentes perspectivas, diferentes focalizações.(2008, p. 147). A pergunta "igualdade de que?" parece ter por resposta: Igualdade de capacidade para realizar funcionamentos.

\section{3- LEIS ÉTICAS COMO FUNDAMENTO DAS AÇÕES ORIENTADAS AO BEM SUPREMO}

No livro I de "Ética à Nicômaco", Aristóteles $(1991,1)$ afiança serem todas as ações e todas as escolhas almejantes de um bem qualquer: todas as coisas tendem para o bem. Continua o filósofo (1991, livro I, 2), declarando que as ações voltadas para um fim em si mesmo e todo o realizado no interesse deste fim, farão deste fim o bem, ou o sumo bem.

Entendendo a política como uma determinante das ciências que devem estudar o Estado e também como a legislação acerca das ações permitidas ou proibidas, o autor (1991, livro I, 2), vê a finalidade desta como abrangente à de todas as outras ciências, declara ser escopo da política o bem humano. 
Tendo admitido que todo conhecimento e todo trabalho visam o bem, Aristóteles (1991, livro I, 4) identifica o sumo bem como a felicidade. Por felicidade, no sentido de bemestar, entende-se tudo o que é procurado por si mesmo, sem vistas à outras coisas, gozando o bem supremo, então, de autossuficiência, sendo aquilo que, em si mesmo, torna a vida desejável, sem carecer de mais nada, sem ser contada como mais um bem entre outros, consagrando-se a finalidade da ação. (ARISTÓTELES, livro I, 7).

Ajustar-se-ia à concepção de felicidade a ideia de que o homem feliz vive bem e age bem e, ainda, de que se conforma a felicidade com virtude perfeita, convidando, pois, Aristóteles (1991, livro I, 13) à melhor compreensão da natureza da virtude.

Partindo ao Livro II, 1, conhece-se a virtude moral como o resultado adquirido através do hábito, não surgindo nas pessoas por natureza, afinal “(...) nada do que existe naturalmente pode formar um hábito contrário à sua natureza”. Esclarece-se, ainda, que a 
mesma relaciona-se com a escolha e consiste, como substância e a definição estabelecedora de sua essência, em uma mediania, um meio termo entre dois vícios, um por excesso e outro por falta. Contudo, no que se refere à justiça e ao sumo bem, a virtude é um extremo, afinal é o seu alcance que levará à felicidade (ARISTÓTELES, 1991, livro II, 6).

No livro V, Aristóteles passa a tratar da justiça, considerando-a a maior das virtudes, na qual estão compreendidas todas as outras virtudes, gozando de completude porque o possuidor desta virtude pode exercê-la para além de si mesmo, fazendo-a agir sobre o próximo. A grandeza da justiça está no fato de que muitos homens podem ser virtuosos em seu âmbito privado, mas relacionar a virtude à outras pessoas, tal como requer a atitude justa, é tarefa mais difícil (ARISTÓTELES,1991, 8). Pelo exposto, pondera-se a justiça, entre todas as outras, como o "'bem do outro"”, pois se relaciona ao próximo e ao que lhe é vantajoso, configurando-se como virtude inteira e a injustiça, o vício inteiro.

Aristóteles (1991, livro V, 2), contudo, afirma ser o seu objeto de investigação "as justiças" que constituem as partes da virtude "justiça completa", quais sejam a justiça que se manifesta na distribuição de honrarias, de dinheiro ou das outras coisas que são divididas entre aqueles que tem parte na constituição, sendo a outra espécie exerce a correção nas transações entre os indivíduos. A este trabalho interessa a primeira categoria apresentada, chamada justiça distributiva, tal como a promovida pelas teorias de Rawls, Dworkin e Sen.

A partir da divisão efetuada, o filósofo (1991, livro V, 3) passa a tratar da justiça distributiva, compreendendo por justo o que é equitativo, compreendendo-se por equidade o ponto intermediário entre a iniquidade e o ato justo. Aristóteles completa seu pensamento aplicando a equidade às pessoa, quando já tratara das coisas, dizendo: "Se não são iguais não receberão coisas iguais(...)".

Ora, a concepção de justiça distributiva enunciada nos preceitos de igualdade liberal é claramente aristotélica, mas o encadeamento racional e livre, próprio ao liberalismo político, em que, nas palavras de Robinet (2004, p. 166), “o indivíduo tem um valor infinito", não mais pode ser apontado como parte da ética clássica, consubstanciando-se, pois no pensamento kantiano.

$\mathrm{Na}$ "Metafísica dos costumes", Kant (2003, p. 58) considera os preceitos da moralidade como comandos gerais, a partir dos quais são afastadas as inclinações da paixão, pois, a liberdade e a razão prática, inerentes a todo ser humano permitem que o conhecimento 
não se dê desde a natureza animal humana ou percepção dos modos do mundo, mas sim da razão que direciona a ação do homem, mesmo diante da falta de exemplos.

O sistema de cognição a priori, diz-nos Kant (2004, p. 58), é a metafísica e imprime as condições para a filosofia prática que não busca seu objeto na natureza, mas na liberdade de escolher. Para a metafísica dos costumes, então, há no interior do ser humano, aprioristicamente, uma lei universal.

O conceito negativo da liberdade para escolher adviria da independência dos homens de seus impulsos sensíveis, em contra partida, o conceito positivo de liberdade refere-se à condição da razão pura do homem, cuja existência não encontra correspondência em nenhum exemplo, mostrando-se, por si mesma, prática e condicionante para que uma ação possa ser qualificada como lei universal. (KANT, 2004, p.63).

Diferentemente das leis de natureza, as leis de liberdade são, para o pensamento kantiano, leis morais e, conforme seja requerido de tais leis que fundamentem determinantemente as ações, passam a ser cunhadas como leis éticas. Portanto pode a liberdade, a qual estas leis fazem referência, ser parâmetro para o uso externo da escolha, isto é, quando a ação direciona-se para se conformar às leis externas, quanto para o uso interno da escolha, quando a ação é determinada por uma lei da razão. (KANT, 2004, p.63-64).

A liberdade, para a filosofia kantiana (2004, p. 64), é um conceito racional puro para o qual deve se voltar a razão prática que, por conseguinte, o comprova por meio de princípios práticos configurados em leis determinantes da escolha, cuja realidade independe das contingências empíricas e revela a vontade pura do indivíduo. O conceito positivo de liberdade baseia as leis práticas, também conhecidas como leis morais ou imperativos categóricos, com a função de comandar ou proibir, conforme a razão pura, incondicionalmente.

Para Kant (2004, p. 64-65), então, os imperativos categóricos permitem ou proíbem as ações em acordo com as possibilidades morais desta, extraindo-se da razão pura as condutas moralmente obrigatórias. A obrigação, na filosofia kantiana, é a necessidade de uma ação livre subordinada a um imperativo categórico, o qual condiz com uma ação executada, dada a necessidade interna do agente e a correspondência com seu perfil de regra, através da qual o ser humano é constrangido a agir em conformidade. O imperativo categórico "é aquele que representa uma ação como como objetivamente necessária e a torna necessária não indiretamente através da representação de um fim que pode ser atingido pela ação, mas através da mera representação dessa própria ação (...).”. 
O fundamento do imperativo categórico para Kant (2004, p. 65-66) é a liberdade, posto que a personalidade moral nada mais é que liberdade de um ser racional submetido às leis morais, portanto, todas as pessoas estariam submetidas à leis morais auto-impostas.

O primeiro imperativo categórico formulado por Kant (2004, p. 67-68) é: “Age com base em uma máxima que também possa ter validade como lei universal.", devendo-se, a partir do postulado, avaliar as ações primeiramente em termos subjetivos e somente praticálas caso caibam na objetividade do primeiro imperativo categórico.

Claro é que a "Metafísica dos Costumes" estende-se em maiores ilustrações racionais sobre a ética, mas o intuito do estudo não é deslindá-las, e sim fazê-la de instrumental para apontar a igualdade como ideal ético para a comunidade, tal como se buscará demonstrar no tópico que segue.

\section{4 - A ÉTICA DA IGUALDADE}

Quando Rawls (2008, p.3), na primeira página do capítulo 1 de sua obra, impõe que sua teoria descreve o papel da justiça na cooperação social e apresenta uma breve explanação acerca do objeto principal da justiça, isto é, a estrutura básica da sociedade, tem-se que uma teoria política está por vir. O mesmo ocorre quando Dworkin (2011, p. 3) e Sen (2008, p. 43) referem-se, respectivamente, à igualdade como “ideal político popular" e como uma exigência de todo teoria normativa do ordenamento social que haja resistido ao tempo.

Todos os autores, por serem declaradamente liberais, sustentam a igualdade como um princípio da justiça que levará à realização dos planos de vida, da vida boa ou da vida que se escolheu. Assim, para Rawls (2008, p. 526) a consecução do plano de vida de um membro de uma sociedade justa também somente será alcançado se estiver em acordo com as restrições do justo; enquanto para Dworkin (2011, p. 335 e 345) a fonte da questão ética para a vida boa está na importância objetiva de que a vida seja bem sucedida e que isso seja igual para todas as vidas humanas, cabendo a cada indivíduo a responsabilidade sobre o êxito, sendo a ligação entre os interesses próprios e a moralidade a justiça, como um componente predominante da vida boa que nenhum outro ganho ou componente pode sobrepujar. Por fim, Sen $(2008$, p. 136) em sua concepção de justiça prevê que é o conjunto capacitário o meio capaz de proporcionar liberdade real, configurando-se, portanto, como o justo elemento para que os indivíduos possam escolher dentre as variadas vidas possíveis.

É perceptível, pois, que todas as teorias apontam a justiça como a virtude capaz de promover o alcance dos planos de vida, da vida boa ou da vida escolhida, que são para o 
liberalismo político o sumo bem, a felicidade ou o que é procurado por si mesmo. Dada a liberdade da decisão, consubstancia-se a justiça em uma virtude que precede o bem e sem a qual este não pode se realizar, tal como descrevera Aristóteles.

Ora, se a justiça é a virtude que levará ao bem supremo, qual seja a vida determinada pelo próprio indivíduo, sua concepção é ética, pois deve ser um preceito enraizado na moralidade social para que todos os sujeitos tenham a possibilidade de atingir o bem supremo.

Averiguada a justiça como parte da substância ética, é de se questionar acerca de seu componente sob estudo, a igualdade. Como já é possível observar, através da breve compilação das teorias liberais igualitárias, realizada em tópico anterior, a máxima da justiça distributiva, enunciada por Aristóteles, "tratar os desiguais com desigualdade" é aproveitada e aprofundada na liberdade igualitária, sendo a igualdade, por conseguinte um fundamento ético da sociedade, porque é o componente que orienta, fundamentalmente, a justiça distributiva na qual a justiça, como virtude completa, divide-se. Sem a igualdade - como elemento ético, como princípio cristalizado de uma comunidade - em uma economia de livre mercado, os indivíduos poderiam não ter a oportunidade de alcançar e até mesmo de buscar seus planos de vida, caso fossem limitados por contingências de natureza arbitrária, tal como uma deficiência física, cujo acontecimento independe da liberdade individual, o corolário do liberalismo político.

A igualdade alcança, assim, sua condição de fundamento ético social quando propicia à sociedade uma distribuição mínima de recursos, bens primários ou conjunto capacitário, os quais possibilitam, ao todo do corpo político, suprir suas necessidades de maneira que consigam encaminhar-se na busca pela vida boa, conforme esta se apresente em acordo com os interesses individuais de cada componente social. Interessa, politicamente, a igualdade de bens primários, de recursos e de capacidade para realizar funcionamentos, porque a sociedade necessita de instituições promotoras da boa vida ou então estas não teriam razão de existir, uma vez que o fim ético buscado por todo ser humano é, tal como nos diz o liberalismo de princípio, a felicidade, cuja consecução somente é exequível, caso a suprema das virtudes, isto é, a justiça faça-se presente nas instituições políticas, tal como as instituições jurídicas, e promova a igualdade como seu componente basilar e indispensável.

Embora a igualdade como fundamento ético da sociedade política já esteja apresentada, é de se questionar por que os indivíduos, mutuamente desinteressados e responsáveis por seus planos de vida (como expõem todas as teorias com maior e menor ênfase), deveriam se preocupar com a igualdade para a estrutura básica da sociedade? Isto é, 
em sendo a tônica do liberalismo o valor infinito do indivíduo qual a razão destes preocuparem-se com os outros integrantes da sociedade, qual o raciocínio que eleva a igualdade como um bem coletivo e a necessidade de se ter um bem coletivo?

Quando se compreende, a partir da "Metafísica dos costumes" de Kant que a liberdade é um produto da razão pura que também deve ser prática, entende-se, em consequência, que a liberdade como razão pura ganha concretude quando se revela a vontade do indivíduo livre das inclinações sensíveis e em acordo com as leis éticas, cuja determinação se dá através da razão, isto é, através da imposição de leis morais do sujeito para si mesmo dada a sua liberdade - . Esta autoimposição leva ao imperativo categórico de se agir com base em uma máxima que possa ter validade universal, afinal a razão prática e, consequentemente, a liberdade dota todos os seres.

Desta maneira, o raciocínio ético para se chegar à igualdade, em acordo com as teorias de igualdade liberal, é de que esta seria uma máxima universal de caráter racional, isto é, a igualdade da justiça distributiva, permissora da busca pela felicidade é algo que um ser racional e livre quereria para si, logo a igualdade deve ser uma lei ética de validade universal, na qual se funde este querer primariamente individual. Em sendo uma lei ética de validade universal, é racional que todos os outros indivíduos, livres e racionais ajam amparados neste mesmo parâmetro.

Além disso, as teorias de igualdade liberal deixam bem claro, desde sua concepção da natureza humana individualista, que a igualdade como princípio não permite que ninguém, mesmo tendo nascido desfavorecido conforme a sorte da loteria natural, fique privado das vantagens que tornam realizável a vida boa. Logo, garantir a igualdade para todos é garantir a igualdade para mim mesmo e assegurar minhas próprias chances de felicidade.

\section{5 - NOTAS SOBRE POLÍTICA E FILOSOFIA DO DIREITO}

Este tópico não pretende esgotar o tema acerca da moralidade política e sua ligação com o direito; afinal, um longo debate acerca de teorias juspositivistas, jusnaturalistas e hermenêuticas seria aqui travado, não interessando para as argumentações já expostas e sua coadunação à filosofia do direito. Importa sim, apresentar como a política, substrato dos preceitos de igualdade liberal, informa a crítica do direito, sua filosofia, para que este, enquanto teoria, oriente o direito enquanto instituição ou ordenamento jurídico.

A leitura das obras de Ronald Dworkin fazem crer que sua teoria do direito não se aparta de conteúdo moral, nem priva a jurisdição da interpretação quando da solução de casos 
concretos, sendo esta mesma aplicação, e consequente interpretação, uma estratégia de reconhecimento de novos direitos.

Em "O Império do Direito", o autor (2003, p. 3-4) inicia seu pensamento afirmando que "a dignidade e a ruína" podem depender de "um aceno de cabeça do juiz" e que os processos judiciais possuem uma inevitável dimensão moral associada, constituindo-se em um dano moral social que um julgamento seja injusto.

Neste sentido, quando Dworkin (2003, p. 5) assegura que os processos judiciais suscitam questões de fato, de direito e de moralidade, está se posicionando contra as ideias positivistas de separação entre direito e moral. Quando afirma (2003, p. 8), em seguida, que as proposições jurídicas possuem divergências empíricas facilmente sanáveis, mas que as divergências quanto aos fundamentos é que se revelam problemáticas, uma vez mais se afasta do positivismo, destituindo categoricamente o "direito como simples questão de fato".

Compreendendo a insuficiência das teoria semântica jurídicas (2003, p. 38), cujas regras ligam o direito ao fato histórico puro e simples, o autor (2003, p. 50) afirma ser impensável que as decisões sobre o poder do estado sejam um mero jogo de palavras, uma vez que existem divergências teóricas dentro das proposições jurídicas. Na obra "Justiça de Toga", em resposta ao positivista Herbert Hart (2010, p. 200), ensina que uma teoria válida sobre o direito não constitui uma descrição neutra da prática jurídica, mas sim uma interpretação descritiva e justificada que mostre o porquê de a prática ser valiosa, além de significar o embasamento da teoria jurídica em julgamentos e convicções éticas.

A interpretação jurídica proposta por Dworkin (2003, p. 112) é, pois, construtiva, cabendo aos juízes, como autores (frise-se que o autor escreve desde um sistema de commom law) tentar apresentar o conjunto da jurisdição sob a melhor luz quanto ao equilíbrio e a melhor justificativa, estando esta melhor luz na integridade do direito como ideal político, isto é, na união com a vida política do cidadão (2003, p. 230), sendo as proposições jurídicas verdadeiras "se constam ou se derivam dos princípios da justiça, equidade e devido processo legal" (2003, p. 272), pois são estes os princípios basilares para a melhor interpretação construtiva, são estes princípios, em verdade, que devem condicionar as decisões.

A partir das colocações acima mencionadas e da reafirmação em "Justiça para Ouriços" (2012, p. 501) que os indivíduos possuem direitos políticos, sendo alguns destes correspondentes aos deveres coletivos da comunidade - restando, assim demonstrada a integridade política e moral - e , ademais, que a ideia de direitos políticos pode ser usada para expressar os interesses individuais, sumamente importantes, cuja proteção pode ser dar, 
inclusive, contra políticas de proteção à toda comunidade, configurando-se tais direitos em verdadeiros trunfos contra ações políticas inadequadas.

Esta ideia de interpretação construtiva em que juízes são ao mesmo tempo autores e críticos que se voltam ao passado para sopesá-lo junto a contemporaneidade, sempre à luz do ideal político do direito como integridade, remete à afirmação do autor (2003, p. 259) de que este ideal político se adapta e explica a estrutura prática constitucional, cabendo a esta jurisdição reconhecer direitos constitucionais que os fundadores não haviam previsto (2003, p 438), dentro da estabilidade que é a integridade do direito (2003, p. 441), já se podendo compreender desta pauta a estratégia jurisdicional dworkiniana de reconhecimento de novos direitos.

Dworkin, então (2012, p. 512) não se coloca alheio ao à dignidade de cada indivíduo, o que, por conseguinte é fundamento para que cada ser humano - cumprindo frisar a inclusão das minorias dentro da lógica constitucional-democrática - tenham esta dignidade garantida.

O direito como integridade, diante do elucidado, não se olvida da ética da pólis; ao contrário, reconhece nesta a chave para a justiça, equidade e o devido processo legal. Não é sem razão, pois, afirmar que a filosofia do direito erigida por Dworkin é capaz de sustentar o direito como legitimador da justiça distributiva que pode se valer de ações afirmativas, por exemplo, para a promoção da igualdade, através da diversidade - como teorizam as correntes liberais igualitárias - como "um objetivo socialmente mais importante", tal qual enuncia Sandel (2013, p. 213).

\section{6 - CONCLUSÃO}

As conclusões às quais se chegam não poderiam ignorar a pergunta feita na introdução: "Por que a igualdade importa para a ética da comunidade política?" , isto é, por que a investigação da ética da pólis perpassa pela igualdade como parte constituinte das ações das instituições que disciplinam e organizam a vida em sociedade?

Como já ilustrado, todos os autores buscam a igualdade preservando as diferenças dos indivíduos, entendendo-a como um princípio da justiça que respeita ou funda a liberdade para ser desigual. Nesta vereda, nas teorias elencadas, as instituições políticas refletem ou representam a sociedade que é desigual e, tal como se apresentou o último teórico do trabalho, o ordenamento jurídico, como instituição social que é, também deve acompanhar os preceitos da política para servir a comunidade, tal qual esta precisa e almeja racionalmente. 
A igualdade é, então, um ideal ético das instituições sociais, pois sem a mesma a justiça como virtude que se encaminha para o bem supremo ou à vida boa de cada um - na qual se realizam os planejamentos que importam à cada pessoa - careceria de sua face distributiva e estaria, pois incompleta. Além disso, seria incompatível com a natureza racional e livre do ser humano não querer a igualdade, afinal, adotando a perspectiva kantiana, a igualdade precisa ser uma lei ética universal, pois assim como um indivíduo compreende racionalmente que suas desigualdades devem, não somente ser respeitadas, mas também compensadas caso desvantajosas, para que possa ter a liberdade de buscar a vida boa, a mesma lógica deve valer para todas as outras pessoas, afinal sua ação deve estar fundada em uma máxima, uma lei ética, que deva ser um pressuposto de ação para todas as outras pessoas, cuja natureza é a de seres livres e racionais, cujos atos não se perfazem segundo as inclinações dos sentidos, mas segundo os preceitos da moralidade advindos da razão. 


\section{7 - REFERÊNCIAS}

ABBAGNANO, Nicola. Dicionário de Filosofia. Tradução de Alfredo Bosi. 5 ed. São Paulo: Martins Fontes, 2007.

ARISTÓTELES. Ética à Nicômaco. Tradução de Leonel Vallandro e Gerd Bornhein da versão inglesa de W. D. Ross. 4 ed. São Paulo: Nova Cultural, 1991.

BOBBIO, Norberto; MATTEUCCI, Nicola; PASQUINO, Gianfranco. Dicionário de Política - Vol. 1. Tradução de Carmen C. Varriale; Gaetano Lo Monaco; João Ferreira; Luís Cacais e Renzo Dini. 11 ed. Brasília: Editora UNB, 1998.

DWORKIN, Ronald. A justiça de toga. Tradução de Jeferson Luiz Camargo. São Paulo: Martins Fontes, 2010.

A Virtude Soberana: A teoria e a prática da igualdade. Tradução de Jussara Simões. São Paulo: wmf Martins Fontes, 2011.

Justiça para ouriços. São Paulo: Almedina, 2012.

O império do direito. Tradução de Jeferson Luiz Camargo. São Paulo: Martins

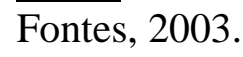

HIRSCHLLER, Ben; Reuteurs. Fórum Econômico Mundial alerta para aumento da desigualdade. Estadão Geral, 2014. Disponível em: < http://www.estadao.com.br/noticias/geral,forum-economico-mundial-alerta-para-aumento-dadesigualdade,1119098>. Acesso em nov de 2015.

KANT, IMMANUEL. A Metafísica dos Costumes. Tradução de Edson Bini. Baurú, SP: EDIPRO, 2003.

RAWLS, John. Uma teoria da justiça. Tradução de Jussara Simões e Álvaro de Vita. 3 ed. São Paulo: Martins Fontes, 2008.

ROBINET, Jean-François. O tempo do pensamento. Tradução de Benôni Lemos. São Paulo: Paulus, 2004.

SANDEL, Michael J.. Jutiça: o que é fazer a coisa certa. Tradução de Heloísa Matias e Maria Alice Máximo, 12 ed. Rio de Janeiro: Civilização Brasileira, 2013.

SEN, Amartya. Desigualdade Reexaminada. Tradução de Ricardo Doninneli Mendes. 2 ed. Rio de Janeiro, São Paulo: Editora Record, 2008. 